\title{
Knowledge about Stroke in Belo Horizonte, Brazil: A Community-Based Study Using an Innovative Video Approach
}

\author{
Fidel Meira $^{a} \quad$ Daiane Magalhães $^{b} \quad$ Luiz Sérgio da Silva ${ }^{c}$ \\ Ana Clara Mendonça e Silvad Gisele Sampaio Silva ${ }^{\mathrm{e}}$ \\ a Stroke Unit, Hospital Risoleta Tolentino Neves, Belo Horizonte, Brazil; b Universidade \\ José do Rosário Vellano, Alfenas, Brazil; ' Universidade Federal de Viçosa, Viçosa, Brazil; \\ dUniversidade de Itaúna, Itaúna, Brazil; e Universidade Federal de São Paulo, São Paulo, \\ Brazil
}

\section{Keywords}

Stroke education · Risk factors · Stroke in developing countries · Stroke knowledge

\begin{abstract}
Background and Purpose: Stroke is a leading cause of death in Brazil. Knowledge about the clinical manifestations of stroke as well as its risk factors and its management is still poor in the country. We intended to assess the stroke knowledge of an urban population in Belo Horizonte, Brazil. Methods: Individuals assisted by a basic health unit were interviewed between February and August 2014. After demographic data collection, the participants were asked to watch a video that consisted of a person presenting stroke signals and they were asked to answer questions about the condition shown on the video. Afterwards, they answered a semistructured questionnaire to evaluate their stroke knowledge. Results: A total of 703 people were interviewed (62.1\% female, mean age 46.7 years). Recognition of a person having a stroke on the presented video was achieved by $56.1 \%$ of the subjects. Female sex $(p=0.029)$ and contact with someone who had had a stroke (family member [ $p<0.01]$, neighbor $[p<0.05]$ ) increased the odds of correctly identifying the condition showed on the video. The most commonly mentioned clinical manifestations of stroke were weakness (34.7\%) and speech disturbance (31.6\%). Stroke risk factors that were most named were "unbalanced diet" $(42.3 \%)$ and hypertension (33.7\%). Most participants (66.8\%) said they would call the emergency medical services, while $17.8 \%$ would go directly to a hospital. Only 17 subjects knew thrombolytic therapy for acute stroke. Conclusion: Female sex and a family history of stroke increased the odds of recognizing the signs of stroke. Knowledge about the clinical manifestations, risk factors, and management of stroke was low in the studied population.
\end{abstract}



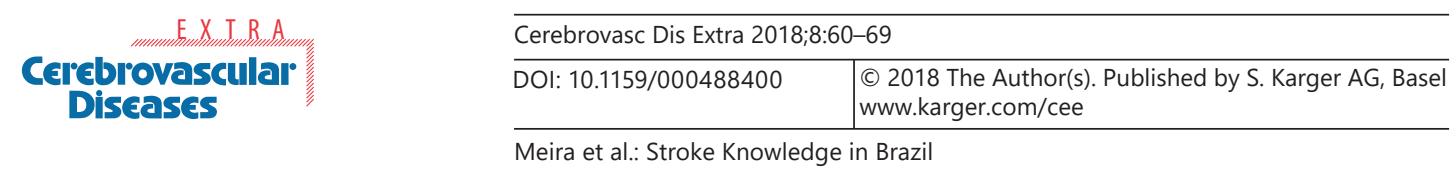

\section{Introduction}

Stroke is the third main cause of death worldwide and one of the main causes of permanent disability among adults in developed countries [1-3]. In Brazil, the incidence of ischemic stroke varies from 105 to $137 / 100,000$ inhabitants, and patients with stroke exhibit high prevalence rates of ischemic heart disease, hypertension, and diabetes mellitus [4-6].

Intravenous administration of tissue plasminogen activator (tPA) to patients with acute ischemic stroke increases the odds of good clinical outcome by $30 \%$ [7]. However, tPA can only be administered within the first $4.5 \mathrm{~h}$ after the onset of an event, which limits the scope of this therapeutic resource. Currently, only $3-5 \%$ of patients diagnosed with ischemic stroke receive tPA treatment $[8,9]$. This low rate is predominantly due to difficulties in the identification of the main clinical manifestations of stroke by the general population [9]. In Brazil, the rate of thrombolytic treatment in systematic studies varies from 1.1\% [10] in the northeastern region and $4.6 \%$ [11] to $8.9 \%$ [12] in the southeast.

Some studies have shown that campaigns on television and in printed materials are good tools to improve the population's awareness about stroke and the need to contact emergency services (in Brazil, Mobile Emergency Care Service - Serviço de Atendimento Móvel de Urgência/SAMU) $[13,14]$. However, multimedia campaigns are usually expensive. Thus, the development of sustainable awareness strategies that may be replicated by governmental agencies, independent organizations, academic societies, and volunteer groups is important [14].

The aim of the present study was to assess the knowledge of a Brazilian urban population about the signs and symptoms of stroke and to evaluate the magnitude of the correlation between this knowledge and independent factors using an innovative approach including a video presenting an acute stroke simulation.

\section{Methods}

The present cross-sectional study was performed in the area covered by the São Bernardo basic health unit located in the northern area of Belo Horizonte (Minas Gerais, Brazil). This basic health unit provides care to 8,343 individuals residing in 2,756 households distributed across three areas according to their socioeconomic level. A total of 673 households were excluded from the study due to inaccessibility, resulting in a final sample of 2,083 households. The interviews were performed between February and August 2014 by trained medical students.

We actively searched for residents of all households in the area targeted by the study. Individuals aged 13-80 years without any condition hindering them from responding to the questionnaire and who agreed to sign an informed consent form were considered eligible. Individuals under 18 years of age had the informed consent forms signed by their legal guardians. All of the targeted households were visited by the researchers, and only one resident per household (usually the first one to answer the door) participated in the study. When the first person that answered the door was unable to answer the questionnaire, the researcher made a random selection among the other residents of the household. Residents who could not be located after two visits and residents who refused to participate were excluded from the study. The sample was stratified according to age range $(01-20,21-30$, $31-40,41-50$, and $>50$ years), education level (measured as years of formal schooling), and sex.

First, the participants watched a video featuring an actor simulating three important signs of stroke: facial asymmetry, upper limb weakness, and speech problems (dysarthria). 
Table 1. Questionnaire applied to the population assisted by São Bernardo basic health unit

\begin{tabular}{|c|c|}
\hline Variables & Aspects evaluated \\
\hline Demographics & sex, age, education level \\
\hline $\begin{array}{l}\text { Recognition of any clinical manifestation shown on } \\
\text { the video as a stroke? }\end{array}$ & $\begin{array}{l}\text { facial asymmetry, upper limb weakness, speech } \\
\text { disturbance }\end{array}$ \\
\hline Previous contact with someone who had a stroke? & family member, neighbor, respondent, none \\
\hline Clinical manifestations of stroke & open-ended question \\
\hline Risk factors for stroke & open-ended question \\
\hline Action to be taken in the setting of an acute stroke & $\begin{array}{l}\text { call EMS (SAMU), go to hospital, go to emergency } \\
\text { department, go to basic health unit, stay at home }\end{array}$ \\
\hline EMS (SAMU) activation & knows EMS telephone number \\
\hline Acute stroke treatment & $\begin{array}{l}\text { knows tissue plasminogen activator, knows time } \\
\text { window for thrombolytic therapy }\end{array}$ \\
\hline
\end{tabular}

EMS, emergency medical service; SAMU, Serviço de Atendimento Móvel de Urgência (Mobile Emergency Care Service).

Then, they were asked to determine which disease best explained the case presented. The participants who mentioned stroke (more than one answer was allowed) were requested to indicate the symptoms that led them to the diagnosis and whether they had had previous contact with a stroke patient. Next, two open-ended questions were posed (one on the clinical manifestations expected in stroke and the second on the main risk factors related to stroke). The questionnaire ended with structured questions on the actions that should be taken upon noticing that someone has just suffered a stroke, whether the participants knew the SAMU phone number, and whether they were aware of the existence of thrombolytic treatment with intravenous tPA (Table 1).

\section{Statistical Analysis}

Data are reported as mean and standard deviation or median or interquartile range when appropriate. Categorical data are reported as absolute and relative frequency of occurrence. Categorical variables were compared with the $\chi^{2}$ or the Fisher exact test. The magnitude of the statistical association between knowledge about stroke and the analyzed independent factors was assessed using odds ratios obtained through logistic regression. The significance level for intergroup differences was set at $5 \%$.

The data analysis was performed in several steps. The first step consisted of a univariate analysis in which all variables that exhibited an association with stroke recognition at a significance level of $p<0.20$ were included. The multivariate analysis was performed in two stages. First, each block of variables (sociodemographic, previous contact with a stroke patient, previous knowledge of the signs and symptoms of stroke, knowledge of risk factors for stroke, and knowledge of actions when witnessing a possible case of stroke) was assessed separately. The variables that exhibited statistical significance at $p \leq 0.05$ were kept in the corresponding block. Next, the blocks were sequentially added into the model in the aforementioned order, and the models with $p>0.05$ after each new addition were eliminated. The final model contained only variables with $p \leq 0.05$. The analysis was performed using the statistical package Stata10 (StataCorp, College Station, TX, USA). 


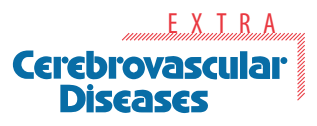

Table 2. Demographic characteristics of the studied population

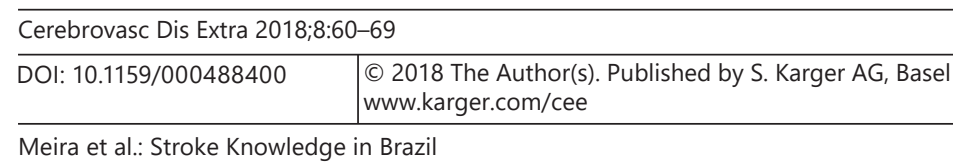

Table 3. Most frequently recognized stroke clinical manifestations and risk factors by the studied population

\begin{tabular}{lclc}
\hline Clinical manifestations & $n(\%)$ & Risk factors & $n(\%)$ \\
\hline Weakness & $244(34.7 \%)$ & Inadequate diet & $297(42.3 \%)$ \\
Speech problems & $222(31.6 \%)$ & Hypertension & $237(33.8 \%)$ \\
Facial asymmetry & $166(23.6 \%)$ & Sedentarism & $199(28.2 \%)$ \\
Headache & $57(8.1 \%)$ & Emotional stress & $169(24.0 \%)$ \\
Memory/cognition problems & $57(8.1 \%)$ & Alcohol consumption & $152(21.6 \%)$ \\
Pain & $45(6.4 \%)$ & Smoking & $148(21.0 \%)$ \\
Dizziness & $32(4.6 \%)$ & Dyslipidemia & $65(9.3 \%)$ \\
Chest pain & $31(4.5 \%)$ & Diabetes mellitus & $61(8.7 \%)$ \\
Dyspnea & $9(1.3 \%)$ & Obesity & $37(5.3 \%)$ \\
Tachycardia & $2(0.3 \%)$ & Family history & $13(1.9 \%)$ \\
& & Advanced age & $7(1.0 \%)$ \\
& & Carotid stenosis & $3(0.4 \%)$ \\
\end{tabular}

TIA, transient ischemic attack.

\section{Results}

From the eligible population, 703 individuals responded to the questionnaire after watching the aforementioned video (23 individuals refused to respond, and none was found at 1,357 households after two visits). Only $56 \%$ of the participants identified the symptoms as corresponding to stroke. A total of 437 participants (62.1\%) were female, 397 (56.5\%) were up to 50 years of age, and 367 (52.2\%) had attended $\geq 9$ years of formal schooling (Table 2).

Recognition of the symptoms shown in the video as corresponding to stroke was more frequent among females $(p<0.05)$. Subjects aged $21-30$ years had a worse performance in stroke recognition $(p>0.05)$. The education level was not associated with a higher rate of stroke recognition (univariate and multivariate analyses).

The clinical manifestations of stroke most frequently recognized by the participants were motor weakness (34.7\%), speech problems (31.6\%), and facial asymmetry $(23.6 \%)$ (Table 3). The participants also related other clinical manifestations to stroke, including headache $(8.1 \%)$, memory or cognition problems $(8.1 \%)$, pain $(6.4 \%)$, dizziness $(4.6 \%)$, chest pain (4.5\%), dyspnea (1.3\%), and tachycardia (0.3\%). 
Table 4. Variables associated with greater recognition of stroke shown on the video

\begin{tabular}{|c|c|c|c|c|}
\hline \multirow[t]{2}{*}{ Variables } & \multicolumn{2}{|c|}{ Univariate analysis } & \multicolumn{2}{|c|}{ Multivariate analysis } \\
\hline & $\%$ & $p$ value & OR (CI) & $p$ value \\
\hline Female sex & 65.6 & 0.03 & - & - \\
\hline Previous contact with a neighbor who had a stroke & 20.6 & 0.02 & - & - \\
\hline Previous contact with a relative who had a stroke & 56.6 & 0.001 & $1.54(1.03-2.30)$ & $<0.05$ \\
\hline Identifies hypertension as a risk factor for stroke & 41.7 & $<0.001$ & $1.84(1.21-2.81)$ & $<0.01$ \\
\hline Identifies diabetes mellitus as a risk factor for stroke & 11.3 & 0.008 & - & - \\
\hline Identifies sedentarism as a risk factor for stroke & 31.6 & 0.04 & - & - \\
\hline Identifies obesity as a risk factor for stroke & 7.2 & 0.03 & - & - \\
\hline Identifies smoking as a risk factor for stroke & 23.9 & 0.05 & $5.82(1.57-21.56)$ & $<0.01$ \\
\hline
\end{tabular}

Table 5. Actions to be taken by the studied population in the setting of a acute stroke

\begin{tabular}{lc}
\hline Actions & $n(\%)$ \\
\hline Call EMS (SAMU) & $468(66.8 \%)$ \\
Go to a hospital & $124(17.8 \%)$ \\
Go to an emergency department & $29(4.2 \%)$ \\
Go to a basic health unit & $19(2.8 \%)$ \\
Stay at home & $7(1.0 \%)$ \\
Knows EMS (SAMU) phone number & $328(46.6 \%)$ \\
Knows fire department phone number & $105(15.0 \%)$ \\
Knows thrombolytic therapy & $17(2.4 \%)$ \\
\hline
\end{tabular}

EMS, emergency medical service; SAMU, Serviço de Atendimento Móvel de Urgência (Mobile Emergency Care Service).

The rate of recognition of the clinical symptoms of stroke shown in the video was higher among the participants with a neighbor $(p<0.05)$ or relative $(p<0.01)$ who had had a stroke in the univariate analysis. Contact with a relative remained significant in the multivariate analyses (Table 4).

The risk factors for stroke most frequently identified by the participants were inadequate diet (42.3\%), hypertension (33.7\%), physical inactivity (28.3\%), emotional stress $(24 \%)$, alcohol use (21.6\%), and smoking (21\%). Hypertension, diabetes mellitus, physical inactivity, obesity, and smoking $(p<0.05)$ were more frequently identified as risk factors for stroke by the participants who identified the disease in the video. In the multivariate analysis, only identifying hypertension and smoking as risk factors for stroke remained as predictors of stroke recognition based on the signs and symptoms presented in the video.

Most participants (66.8\%) said they would call SAMU when facing the situation shown on the video, $17.8 \%$ would go to a hospital, some to emergency care units (4.2\%) or basic health units $(2.8 \%)$. Only $1.0 \%$ of the subjects answered that they would stay at home. A total of $61.6 \%$ of the participants knew the SAMU or fire department service telephone number (Table 5).

Finally, only 17 (2.4\%) participants mentioned thrombolytic treatment for acute stroke, whereas none of the participants was aware of the maximum time interval for this therapy (Table 5). 

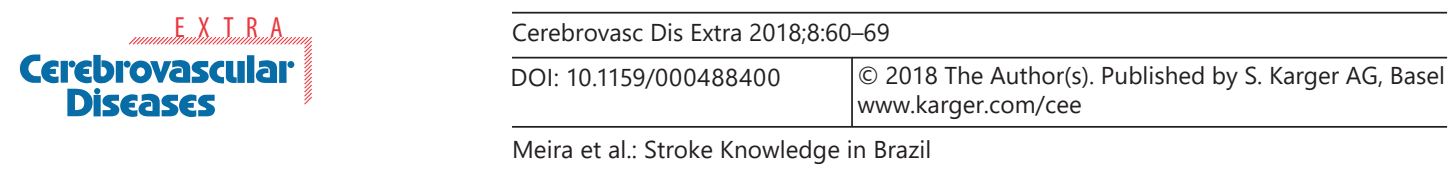

\section{Discussion}

Only a little more than half of the interviewees promptly recognized the symptoms of stroke shown on the video in this community-based study in Brazil. In one study conducted in four Brazilian cities (São Paulo, Ribeirão Preto, Fortaleza, and Salvador), the rate of stroke recognition was $62.2 \%$; however, the authors used a case report that was explained to the subjects, while in the current study a real-life video simulation was used instead [15]. The popular Portuguese term for stroke ("derrame" = spilling) was frequently used by the participants in this series as a synonym for the technical term cerebrovascular accident. In a previous study, $44.0 \%$ of the sample used the expression "derrame," whereas only $23.6 \%$ used the expression cerebrovascular accident and $12.0 \%$ mistook the signs and symptoms for manifestations of acute myocardial infarction [16]. Interestingly, the participants in our study were also confused about these two different conditions. We attribute this finding to the wider access of the overall population to information about myocardial infarction via either the mass media or community-based health promotion actions.

The rate of stroke recognition from the video was not greater among participants with a higher education level. This finding disagrees with the results of other studies in which a higher education level was associated with better knowledge of the clinical manifestations of stroke, greater engagement in primary prevention, and more adequate behavior in the face of acute stroke in other countries [16-19]. One study conducted in São Paulo did not find an association between education level and early arrival of stroke patients to the hospital either [20]. In our study, personal contact with a relative or neighbor with a stroke facilitated the identification of this condition on the video. Practical or visual experience seems to influence the retention of the recognition of stroke symptoms among Brazilians. Thus, educational campaigns including videos similar to the one used in our study might be quite useful for teaching the Brazilian population about the signs and symptoms of stroke.

The warning signs of stroke most frequently recognized in the present study were arm weakness, speech problems, and facial asymmetry. One explanation for this result might be that these were the clinical manifestations shown on the video. Other symptoms such as headache and reasoning/memory impairment might have been described as symptoms of stroke because they were overall related to neurological diseases. The description of pain, chest pain, and shortness of breath as stroke symptoms might be related to the confusion between stroke and myocardial infarction. In one study conducted in Japan, speech problems $(95.5 \%)$ and hemiplegia or hemisensory impairment $(89.5 \%)$ were recognized as the main clinical manifestations of stroke [8]. Adelman et al. [21] also found that paresis (86.9\%) and speech problems (82.9\%) were the main warning signs of stroke identified by the nursing staff at an academic medical center. The rate of recognition of facial asymmetry as a significant sign of stroke varied from 34.7 to $90.1 \%$ in different studies [18, 22].

The participants in our study seemed to associate dietary habits with the occurrence of stroke. An inadequate diet, which according to the interviewees was a diet rich in fat and salt, was the risk factor most frequently mentioned by the participants. Such a dietary pattern is associated with poorer control of hypertension, which is the main cause of stroke. Conversely, several studies showed that a diet rich in fruit, vegetables, fish, and cereals might reduce the risk of stroke [23,24]. Therefore, the identification of this association between diet and stroke in our study might be important in order to identify potential behavior modification strategies based on the current beliefs of our population.

The second most frequently mentioned risk factor for stroke was hypertension. Studies conducted in Brazil (30.1\% [15]) and in other countries (United States, 32.3-49.0\% [25, 26]; Australia, 31.8\% [27]; Luxemburg, 32.0\% [1]; India, 45.1\% [28]) found similar rates. In two studies, one from Japan and the other from Nigeria, the percentage of recognition of hyper- 
tension as the main risk factor for stroke was higher (89.1\% [8] and 87.4\% [29]). Physical inactivity or lack of exercise was an important risk factor for stroke for some subjects. Several studies showed that the practice of physical activity might be directly correlated with a reduced risk of stroke $[30,31]$. About one-fifth of the sample associated stroke with alcohol use and smoking, respectively. In one study performed in Japan, the corresponding rates were much higher (alcohol use 78.2\% and smoking 63.9\%) [32]. This finding reinforces the importance of public campaigns clarifying this relationship in our country.

Some classic modifiable stroke risk factors such as diabetes mellitus, smoking, alcohol use, previous history of stroke or transient ischemic attack, and carotid artery disease were not at all or infrequently recognized by the participants. This was also the case in other studies with designs similar to ours. Indeed, although the latter two risk factors are very important, they were reported by $<1 \%$ of the sample. Conversely, conditions with a weaker relationship with stroke, such as inadequate diet and emotional stress, were mentioned by many participants. The variation in the recognition of risk factors for stroke might be attributed to different local cultural characteristics and the population's exposure to awareness campaigns. For these reasons, culturally adapted individual and collective interventions need to promote more accurate knowledge about the true impact of stroke risk factors, such as hypertension.

A large proportion of the participants in the present study reported that they would call an emergency medical service (EMS) if they were near someone with a stroke. This proportion was higher than the proportion reported by other authors who assessed EMS activation in patients with suspected stroke in other developing countries $[15,16]$. Studies performed in developed countries showed a high percentage of EMS activation for patients with stroke [22, $27,32,33]$, with percentages reaching $89 \%$ in Luxemburg [1]. These data have a crucial relevance because transportation and care by EMS enables patients to arrive faster to healthcare services able to provide treatments that are effective at reducing the damage caused by stroke and thus improving functional outcomes [34]. Approximately $17.6 \%$ of the participants said they would take individuals with stroke directly to a hospital without SAMU activation because this might assist the patients in arriving at an adequate therapeutic facility more quickly. Nevertheless, this practice is not recommended due to the risks associated with patient transport and the possible selection of a service that might not be prepared for the treatment of stroke. This behavior was also reported in other studies conducted in Brazil at even higher rates $(27.8-38.7 \%)[15,16]$. Brazilian studies that assessed the actual mode of arrival of stroke patients to hospitals revealed an even more worrisome situation, with only $18 \%$ of the patients arriving via SAMU [20,35].

Few participants reported behaviors that would result in delayed diagnosis and treatment of patients with stroke, such as taking them to basic health units (where the clinical diagnosis might be established but there are no resources for specific treatment for stroke) or staying at home. Curiously, in a study performed in Japan, the authors found that a large proportion of participants (41.8\%) would prefer to call their family doctor [8]. In one study conducted in Germany, the proportion of participants who indicated that the first action in the case of stroke should be calling an EMS increased from 74 to $84 \%(p<0.001)$ following an educational intervention [36]. In our study, only $61.6 \%$ of the sample knew the phone numbers of the EMS (SAMU and/or fire department service units). This proportion is too low considering the relevance of this type of information, but nonetheless is much higher than the proportion found in a study performed in other Brazilian cities (34.6\%) 11 years ago [15].

Few subjects mentioned thrombolysis as a potential treatment for acute stroke, but none of these participants knew the maximum time interval for the onset of treatment. This finding is similar to the proportion found by a previous study performed in Brazil and is lower than the proportion reported by the authors of a hospital-based study conducted in São Paulo [20]. 
In one Chinese study, $23.3 \%$ of the participants were aware of tPA, and $59.9 \%$ knew the time window [37]. In a similar study in Italy, $26.2 \%$ of the sample knew about alteplase [33].

As its main limitation, this study was performed in a single Brazilian city, and thus the results might not accurately reflect the situation across the country. Another limitation that we faced is the low response rate (only 703 respondents in 2,083 households), but the main reason for this fact is that the researchers visited the inquiry area during business hours, a moment in the day when many residences were empty. We considered the possibility of trying to reach a larger sample of the studied population using e-mail and social media, but there was significant apprehensiveness that we might not find enough engagement of the studied population using theses methods. Nevertheless, the study was performed directly in the community instead of using a convenience sample. Another strength of the present study was the use of a video in which an actor simulated some of the clinical signs of stroke. This type of resource simulates the real situation experienced by people witnessing an episode of stroke and therefore can be more accurate in reflecting participants' reaction when facing it. Besides, the video approach can even provide a new tool for the dissemination of meaningful information such as stroke signals.

\section{Conclusion}

This was the first study evaluating stroke knowledge using an innovative video approach. The results of our survey agree with various other studies conducted in Brazil and indicate that the overall population has insufficient knowledge about stroke, its main clinical manifestations, and its risk factors. Studies like ours help to build the evidence to establish the best type of educational intervention and techniques to be used in public campaigns about stroke awareness in the country.

\section{Statement of Ethics}

This study was approved by the research ethic committees of José do Rosário Vellano University and the Belo Horizonte City Government, and written informed consent was obtained from each subject.

\section{Disclosure Statement}

The authors have no conflicts of interest to disclose.

\section{Funding Sources}

This work received no funding. 


\section{References}

1 Droste DW, Safo J, Metz RJ, Osada N: Stroke awareness in Luxemburg: deficit concerning symptoms and risk factors. Clin Med Insights Cardiol 2014;8(suppl 2):9-13.

-2 Flynn D, Ford GA, Rodgers H, Price C, Steen N, Thomson RG: A time series evaluation of the FAST National Stroke Awareness Campaign in England. PLoS One 2014;9:e104289.

-3 Nakibuuka J, Sajatovic M, Katabira E, Ddumba E, Byakika-Tusiime J, Furlan AJ: Knowledge and perception of stroke: a population-based survey in Uganda. ISRN Stroke 2014;2014:309106.

4 Minelli C, Fen LF, Minelli DP: Stroke incidence, prognosis, 30-day, and 1-year case fatality rates in Matao, Brazil: a population-based prospective study. Stroke 2007;38:2906-2911.

5 Cabral NL, Gonçalves AR, Longo AL, Moro CH, Costa G, Amaral CH, et al: Trends in stroke incidence, mortality and case fatality rates in Joinville, Brazil: 1995-2006. J Neurol Neurosurg Psychiatry 2009;80:749-754.

-6 Lange MC, Cabral NL, Moro CH, Longo AL, Gonçalves AR, Zétola VF, et al: Incidence and mortality of ischemic stroke subtypes in Joinville, Brazil: a population-based study. Arq Neuropsiquiatr 2015;73:648-654.

-7 National Institute of Neurological Disorders and Stroke rt-PA Stroke Study Group: Tissue plasminogen activator for acute ischemic stroke. N Engl J Med 1995;333:1581-1587.

-8 Akiyama H, Hasegawa Y: Stroke knowledge: a nationwide, internet-based survey of 11,121 inhabitants in Japan. Intern Med 2013;52:529-537.

-9 Ravenell J, Leighton-Herrmann E, Abel-Bey A, DeSorbo A, Teresi J, Valdez L, et al: Tailored approaches to stroke health education (TASHE): study protocol for a randomized controlled trial. Trials 2015;16:176.

10 de Carvalho JJ, Alves MB, Viana GA, Machado CB, dos Santos BF, Kanamura AH, et al: Stroke epidemiology, patterns of management, and outcomes in Fortaleza, Brazil: a hospital-based multicenter prospective study. Stroke 2011;42:3341-3346.

11 de Carvalho FA, Schwamm LH, Kuster GW, Bueno Alves M, Cendoroglo Neto M, Sampaio Silva G: Get With The Guidelines stroke performance indicators in a Brazilian tertiary hospital. Cerebrovasc Dis Extra 2012;2: 26-35.

12 Kuster GW, Dutra LA, Brasil IP, Pacheco EP, Arruda MA, Volcov C, et al: Outcome determinants of stroke in a Brazilian primary stroke center. Stroke Res Treat 2014;2014:194768.

-13 Fogle CC, Oser CS, McNamara MJ, Helgerson SD, Gohdes D, Harwell TS: Impact of media on community awareness of stroke warning signs: a comparison study. J Stroke Cerebrovasc Dis 2010;19:370-375.

14 Morimoto A, Miyamatsu N, Okamura T, Nakayama H, Toyoda K, Suzuki K, et al: Effects of intensive and moderate public education on knowledge of early stroke symptoms among a Japanese population: the Acquisition of Stroke Knowledge study. Stroke 2013;44:2829-2834.

15 Pontes-Neto OM, Silva GS, Feitosa MR, de Figueiredo NL, Fiorot JA Jr, Rocha TN, et al: Stroke awareness in Brazil: alarming results in a community-based study. Stroke 2008;39:292-296.

16 Cardoso RF, Carvalho CVA, Cortes PC, Junqueira CM, Marques CCS, Pereira ABCNG, et al: Knowledge about stroke in Vassouras-RJ: analysis between population of urban area and rural area. Neurobiologia 2012;75: 100-108.

17 Diez-Ascaso 0, Martinez-Sanchez P, Fuentes B, Diez-Tejedor E: Sociocultural study on the self-perception of stroke and an analysis of doctor-patient communication. Neurologia 2011;26:81-91.

18 Awad A, Al-Nafisi H: Public knowledge of cardiovascular disease and its risk factors in Kuwait: a cross-sectional survey. BMC Public Health 2014;14:1131.

19 Donkor ES, Owolabi MO, Bampoh P, Aspelund T, Gudnason V: Community awareness of stroke in Accra, Ghana. BMC Public Health 2014;14:196.

20 Panicio MI, Mateus L, Ricarte IF, Figueiredo MM, Fukuda TG, Seixas JC, et al: The influence of patients' knowledge about stroke in Brazil: a cross sectional study. Arq Neuropsiquiatr 2014;72:938-941.

-21 Adelman EE, Meurer WJ, Nance DK, Kocan MJ, Maddox KE, Morgenstern LB, et al: Stroke awareness among inpatient nursing staff at an academic medical center. Stroke 2014;45:271-273.

-22 Focht KL, Gogue AM, White BM, Ellis C: Gender differences in stroke recognition among stroke survivors. J Neurosci Nurs 2014;46:18-22.

23 Iso H, Rexrode KM, Stampfer MJ, Manson JE, Colditz GA, Speizer FE, et al: Intake of fish and omega-3 fatty acids and risk of stroke in women. JAMA 2001;285:304-312.

-24 Chiuve SE, Rexrode KM, Spiegelman D, Logroscino G, Manson JE, Rimm EB: Primary prevention of stroke by healthy lifestyle. Circulation 2008;118:947-954.

-25 Pancioli AM, Broderick J, Kothari R, Brott T, Tuchfarber A, Miller R, et al: Public perception of stroke warning signs and knowledge of potential risk factors. JAMA 1998;279:1288-1292.

26 Schneider AT, Pancioli AM, Khoury JC, Rademacher E, Tuchfarber A, Miller R, et al: Trends in community knowledge of the warning signs and risk factors for stroke. JAMA 2003;289:343-346.

27 Sug Yoon S, Heller RF, Levi C, Wiggers J, Fitzgerald PE: Knowledge of stroke risk factors, warning symptoms, and treatment among an Australian urban population. Stroke 2001;32:1926-1930.

28 Pandian JD, Jaison A, Deepak SS, Kalra G, Shamsher S, Lincoln DJ, et al: Public awareness of warning symptoms, risk factors, and treatment of stroke in northwest India. Stroke 2005;36:644-648.

-29 Obembe AO, Olaogun MO, Bamikole AA, Komolafe MA, Odetunde MO: Awareness of risk factors and warning signs of stroke in a Nigeria university. J Stroke Cerebrovasc Dis 2014;23:749-758. 
30 Kiely DK, Wolf PA, Cupples LA, Beiser AS, Kannel WB: Physical activity and stroke risk: the Framingham Study. Am J Epidemiol 1994;140:608-620.

-31 Hu FB, Stampfer MJ, Colditz GA, Ascherio A, Rexrode KM, Willett WC, et al: Physical activity and risk of stroke in women. JAMA 2000;283:2961-2967.

-32 Matsuzono K, Yokota C, Takekawa H, Okamura T, Miyamatsu N, Nakayama H, et al: Effects of stroke education of junior high school students on stroke knowledge of their parents: Tochigi project. Stroke 2015;46:572-574.

-33 Baldereschi M, Di Carlo A, Vaccaro C, Polizzi B, Inzitari D; Promotion Implementation of Stroke Care in Italy Project Working Group: Stroke knowledge in Italy. Neurol Sci 2015;36:415-421.

-34 Saver JL, Smith EE, Fonarow GC, Reeves MJ, Zhao X, Olson DM, et al: The "golden hour" and acute brain ischemia: presenting features and lytic therapy in >30,000 patients arriving within $60 \mathrm{~min}$ of stroke onset. Stroke 2010; 41:1431-1439.

-35 Kuster GW, Bueno Alves M, Cendoroglo Neto M, Silva GS: Determinants of emergency medical services use in a Brazilian population with acute ischemic stroke. J Stroke Cerebrovasc Dis 2013;22:244-249.

-36 Worthmann H, Schwartz A, Heidenreich F, Sindern E, Lorenz R, Adams HA, et al: Educational campaign on stroke in an urban population in Northern Germany: influence on public stroke awareness and knowledge. Int J Stroke 2013;8:286-292.

-37 Yang J, Zheng M, Chen S, Ou S, Zhang J, Wang N, et al: Knowledge of thrombolytic therapy for acute ischemic stroke among community residents in western urban China. PLoS One 2014;9:e107892. 